\title{
The Unknown Path-Evaluating Electronic Resources for Access-Based Collection Development
}

\section{University of North Texas Libraries}

Erin Miller, Electronic Resources Librarian*

Laurel Sammonds Crawford, Coordinator of Collection Development*

Mark Henley, former Contracts Librarian 


\section{Overview}

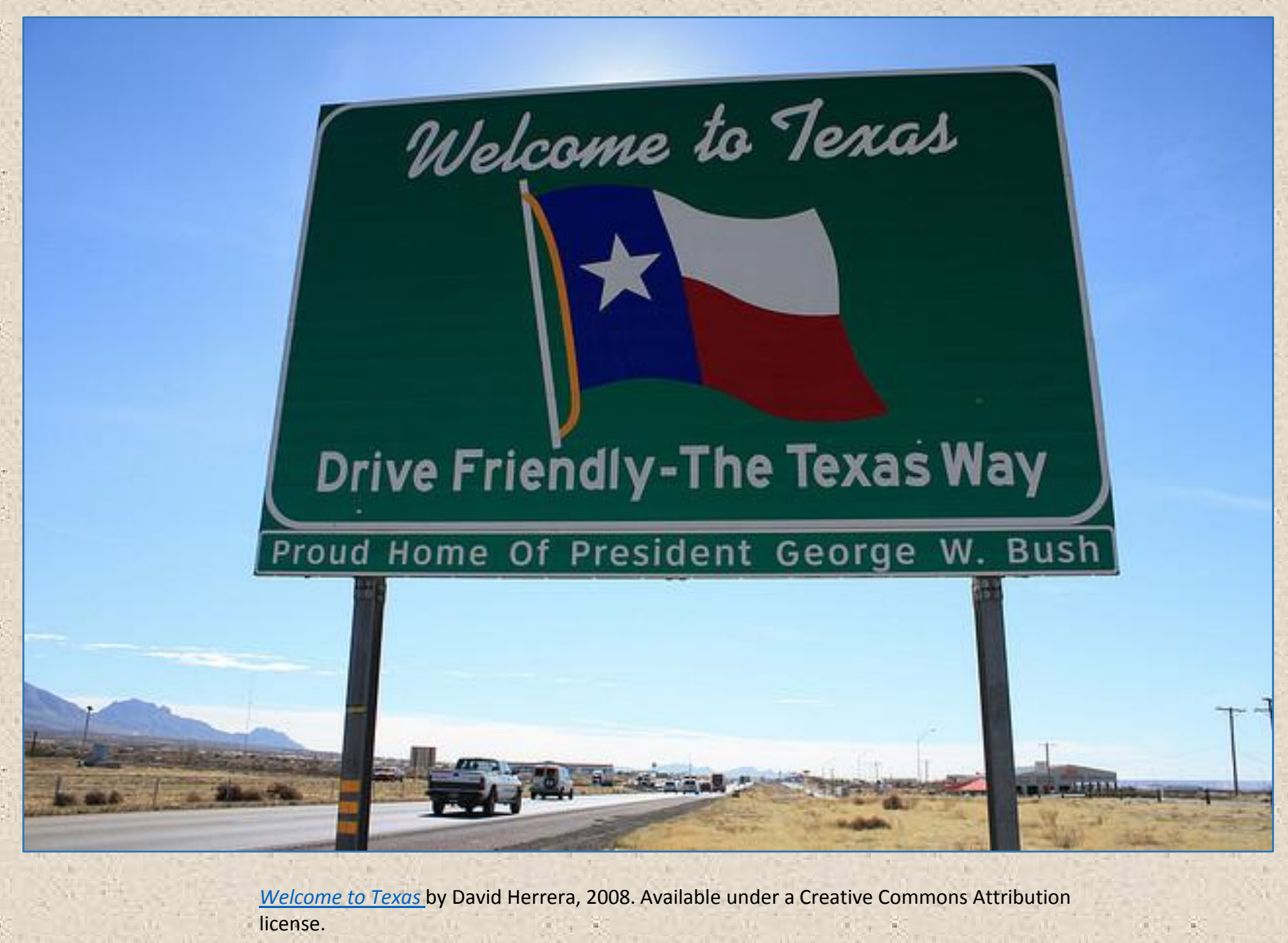




\section{Overview}

Old way

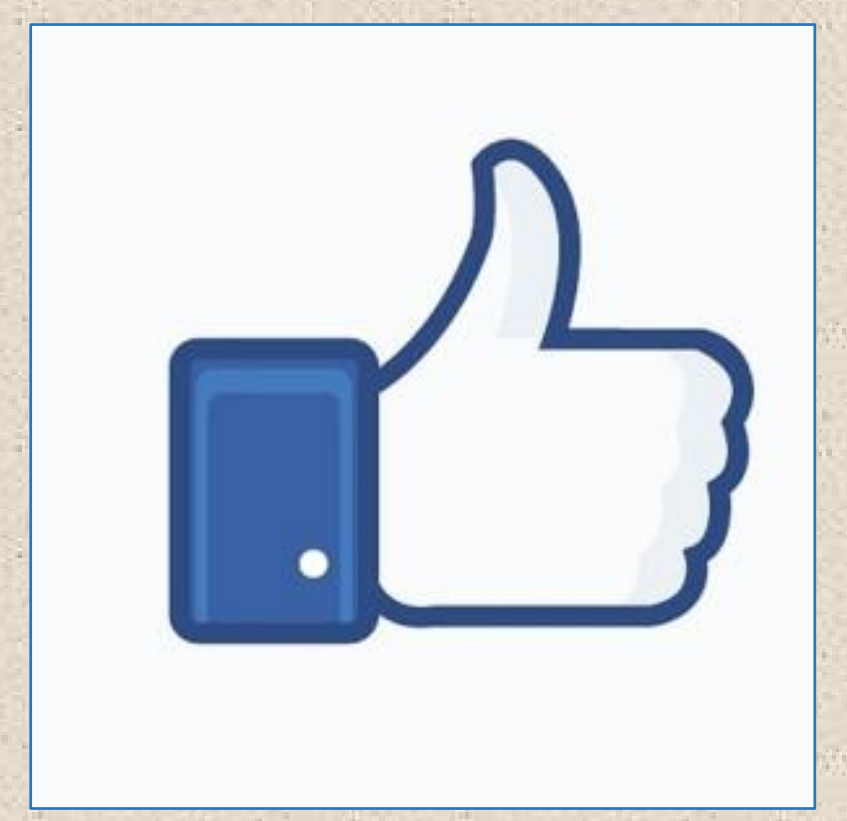

\section{New way}

- Team approach

- Holistic collectionsculpting

- Areas of emphasis

- Evaluation before decision 


\section{Overview}

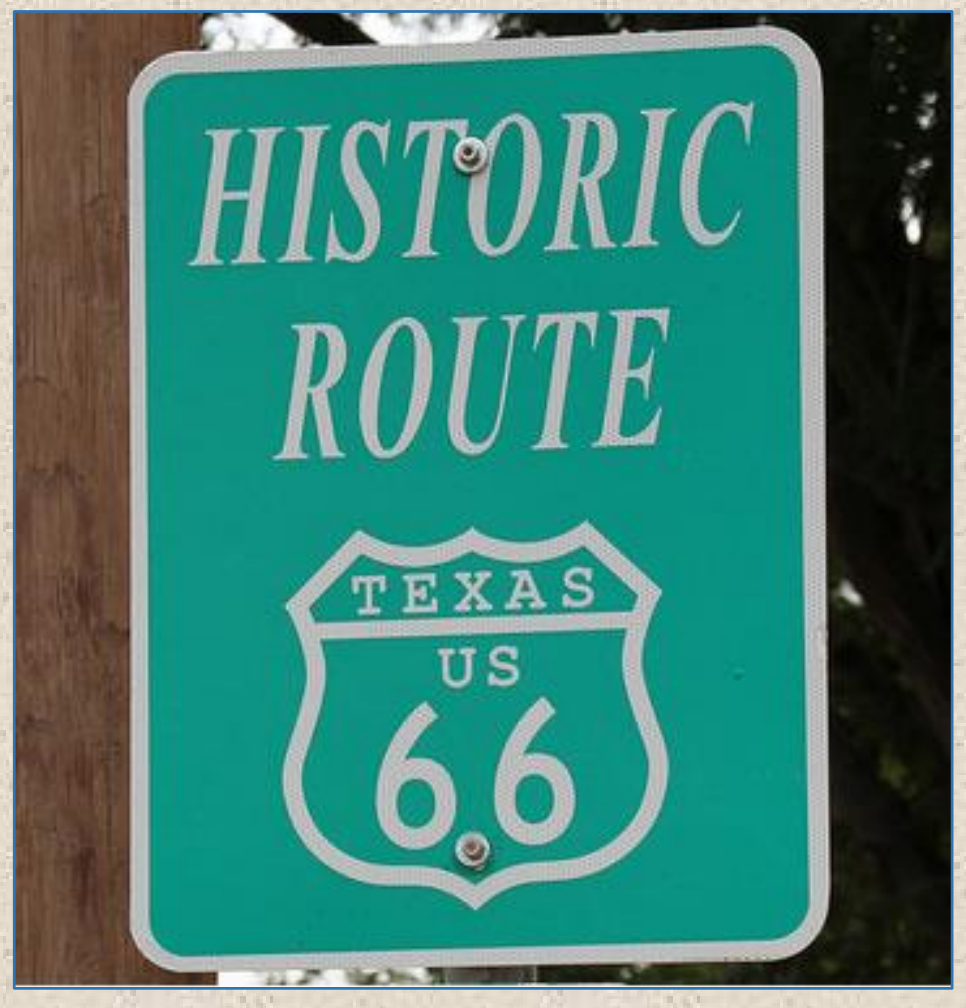

- Evaluation

- Negotiation

- Transparency

- Documentation 


\section{Rubric Overview}

- Ten Criteria Including:

- Feedback

- Trials

- Accessibility

- Content \& Scope

- Library Specific Concerns

- License/Contract*

- Usability*

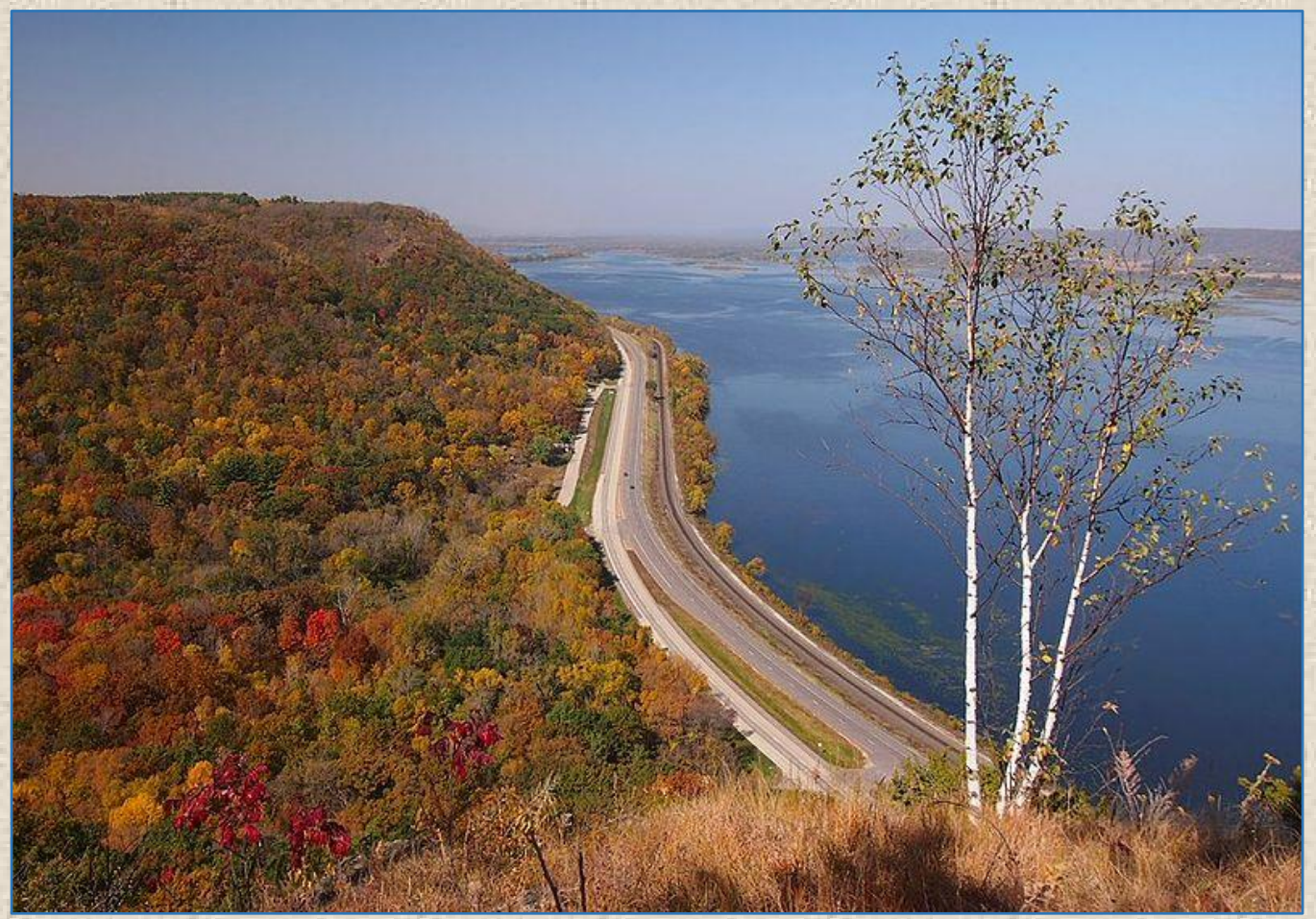

* Lines for licensing and contractual issues and for usability are based on separate, comprehensive checklists. 


\section{Rubric Overview}

\begin{tabular}{|c|c|c|c|c|}
\hline 2 & A & B & $\mathrm{C}$ & $\mathrm{D}$ \\
\hline 1 & \multicolumn{2}{|l|}{ RESOURCE: } & Name: & Date: \\
\hline \multirow[t]{2}{*}{3} & & Excellent & Medium & Poor \\
\hline & Trials results & $\begin{array}{l}\text { Positive and plentiful feedback } \\
\text { from faculty and students; liaison } \\
\text { positively reviewed; high use of } \\
\text { trial }\end{array}$ & $\begin{array}{l}\text { Mediocre but plentiful feedback } \\
\text { from faculty and students; liaison } \\
\text { reviewed as at least not-bad; } \\
\text { medium use of trial }\end{array}$ & $\begin{array}{l}\text { Negative and/or little feedback } \\
\text { from faculty and students; liaison } \\
\text { negatively reviewed; low use of } \\
\text { trial }\end{array}$ \\
\hline 4 & MARC record availability & Available, no cost. & Available, but at a cost. & Not available. \\
\hline & Accessibility & VPAT is filed and available & VPAT available upon request & VPAT not available \\
\hline 6 & & & & \\
\hline & Subject area liaisons' review & $\begin{array}{l}\text { Positive and plentiful feedback } \\
\text { from liaisons; multiple requests to } \\
\text { purchase received }\end{array}$ & $\begin{array}{l}\text { Mediocre feed back from liaisons } \\
\text { OR few or no requests to purchase } \\
\text { received. }\end{array}$ & $\begin{array}{l}\text { Negative feedback from liaisons } \\
\text { and no requests to purchase. }\end{array}$ \\
\hline & Curricular support & $\begin{array}{l}\text { Supports curriculum in multiple } \\
\text { departments; highly } \\
\text { interdisciplinary. }\end{array}$ & $\begin{array}{l}\text { Supports curriculum in at least } \\
\text { one department; slightly } \\
\text { interdisciplinary. }\end{array}$ & $\begin{array}{l}\text { Supports curriculum for only one } \\
\text { highly specific course or none at } \\
\text { all. }\end{array}$ \\
\hline 8 & $\begin{array}{l}\text { Subject coverage context of } \\
\text { holdings and other available }\end{array}$ & $\begin{array}{l}\text { Overlap analysis shows that } \\
\text { subject coverage is not duplicated }\end{array}$ & $\begin{array}{l}\text { Overlap analysis shows that } \\
\text { subject coverage is partly }\end{array}$ & $\begin{array}{l}\text { Overlap analysis shows large } \\
\text { amount of duplication and few }\end{array}$ \\
\hline
\end{tabular}




\section{Feedback}

\section{Subject Librarian Reviews}

\section{Excellent:}

- Multiple requests

- Positive feedback

\section{Poor:}

- No requests

- Negative feedback

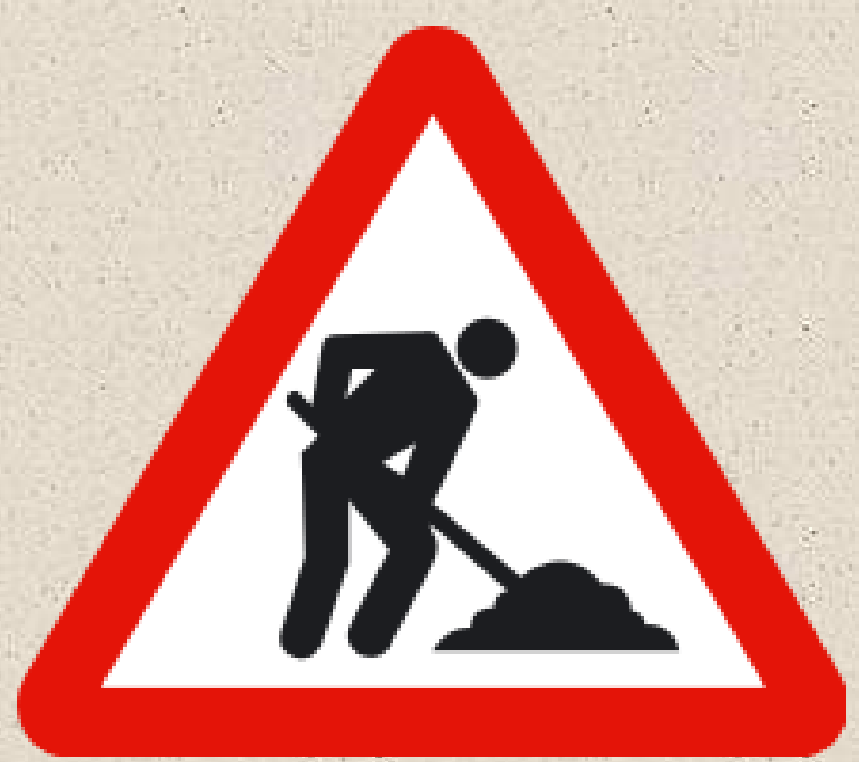




\section{Feedback}

\section{Trials}

Excellent:

- High usage

- Positive feedback \& plenty of it

- Subject librarian involvement

\section{Poor:}

- Low or no usage

- Negative or no feedback

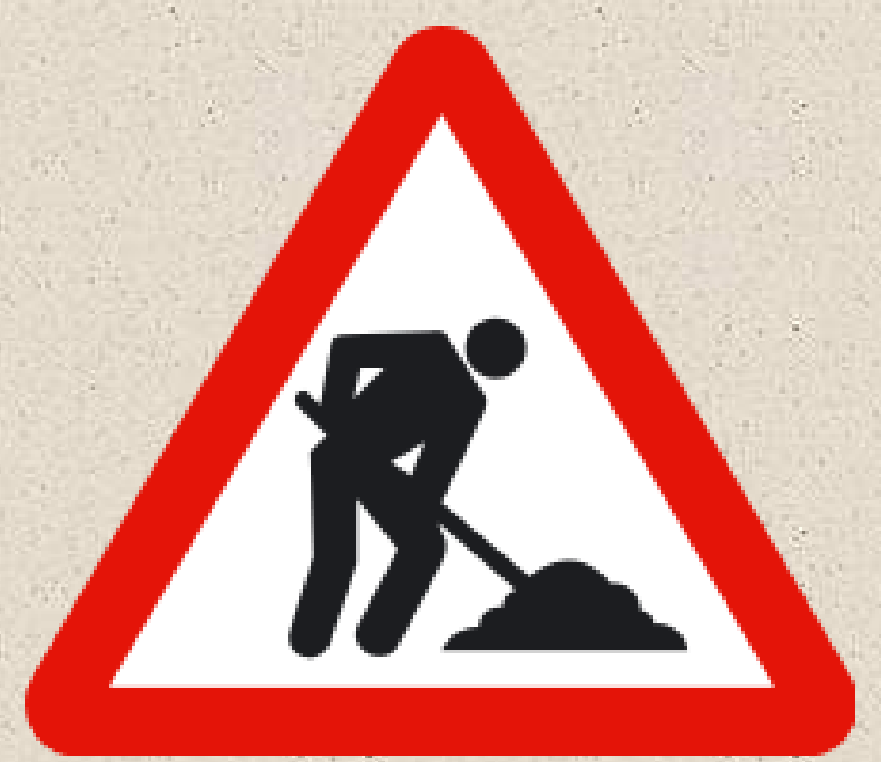

- Lack of interest from subject librarian 
Trials

Feedback and Requests:

- Email

- Qualtrics Survey

- Guidelines

Promote:

- Library Website Homepage

- LibGuide

- Email

- Newsletter

- Monthly liaison meetings

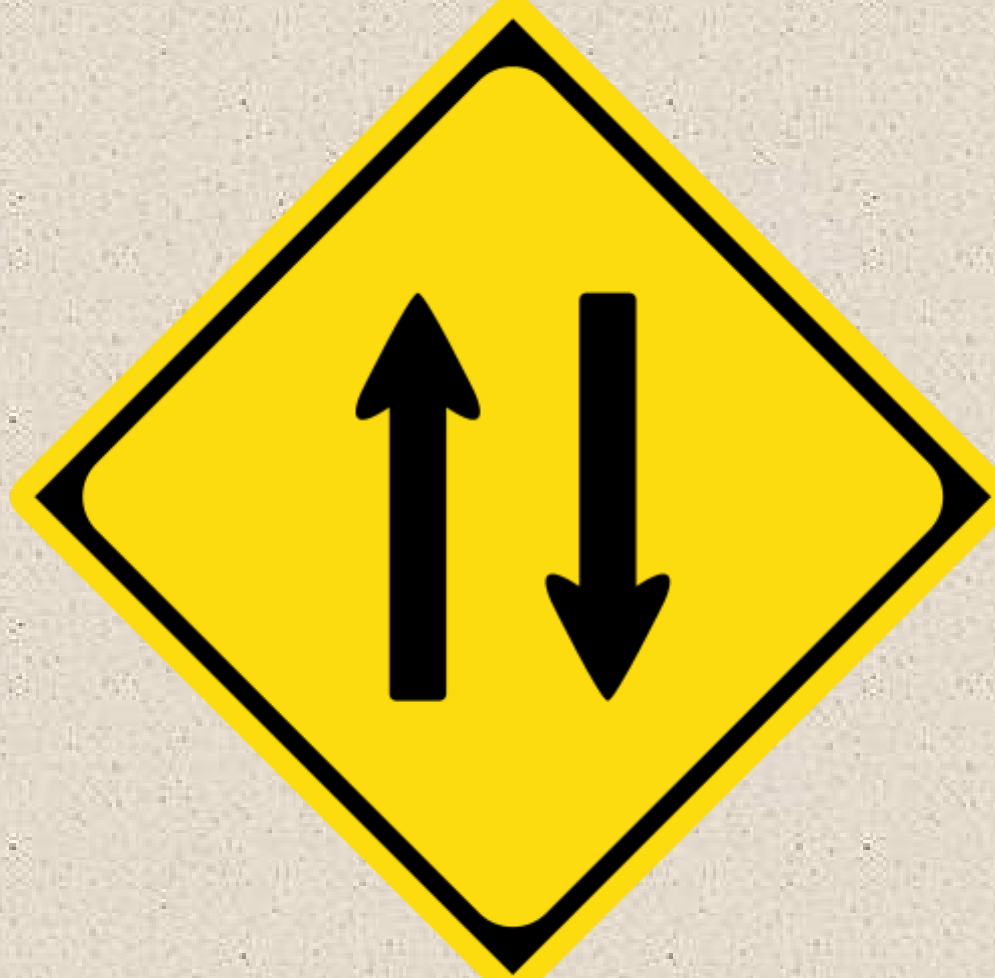




\section{Trials}

\begin{tabular}{|c|c|c|c|c|c|c|c|}
\hline \multicolumn{8}{|c|}{ CURRENT TRIALS } \\
\hline Americana & Victorian & Routledge Handbooks & eHraf & Gale LegalForms & Bernan Digital & Digizeitschriften & Dictionary of American Regional English \\
\hline
\end{tabular}
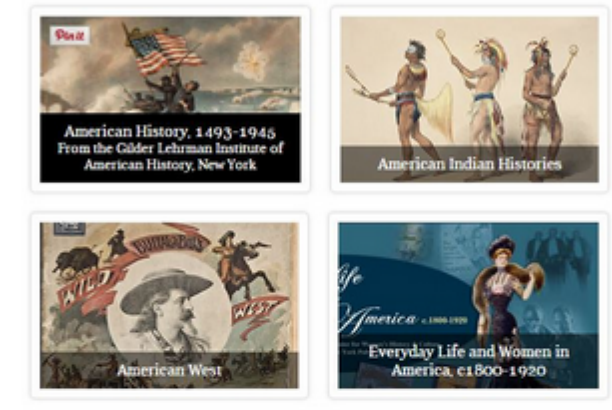

Access the trial at www.americana.amdigital.co.uk until July 7, 2015.

\section{Please provide feedback with this brief survey or by emailing} erin.miller@unt.edu.

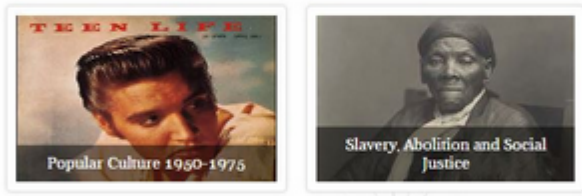

Ranging from Early Contact and the Colonial Period through Revolution and Reform, and the Civil War to Civil Rights, the Explorer platform supports multiple periods and research topics across the Humanities, sourced from a core range of primary source content.

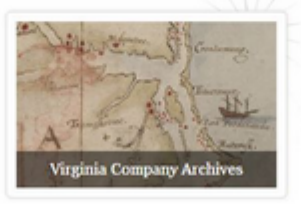

Cross-searchable access to millions of pages of essential American history, literature and culture. Uncover captivating manuscript and typescript letters, diaries, notebooks, journals, newspapers, plus incredible art works, illustrations, photographs, video and 360-degree objects.

Trials and Promotions LibGuide

http://guides.library.unt.edu/ERtrials promotions 


\section{Trials}

\section{Guidelines for Librarians, Faculty \& Students:}



- Trials can be requested at any time during the year

- Limit of 4 concurrent trials

- Faculty \& Students request through Subject Librarian

- Requests will be denied only if:

- Product recently discontinued

- Product recently trialed

- Trials are accepted for:

- New products

- Enhanced products

- Products supporting new programs 


\section{Accessibility}



VPAT -- Voluntary Product Accessibility Template

Rehabilitation Act of 1973

- Supports \& enhances the Americans with Disabilities Act (1990)

- Section 508

- Access to electronic \& information technology

- Federal government regulation:

- Government agencies

- Federally funded nonprofits

- Public education (K-12 and post-secondary)

\section{VPAT Repository:}

\section{http://uniaccessig.org/lua/vpat-repository/}




\section{Content \& Scope}

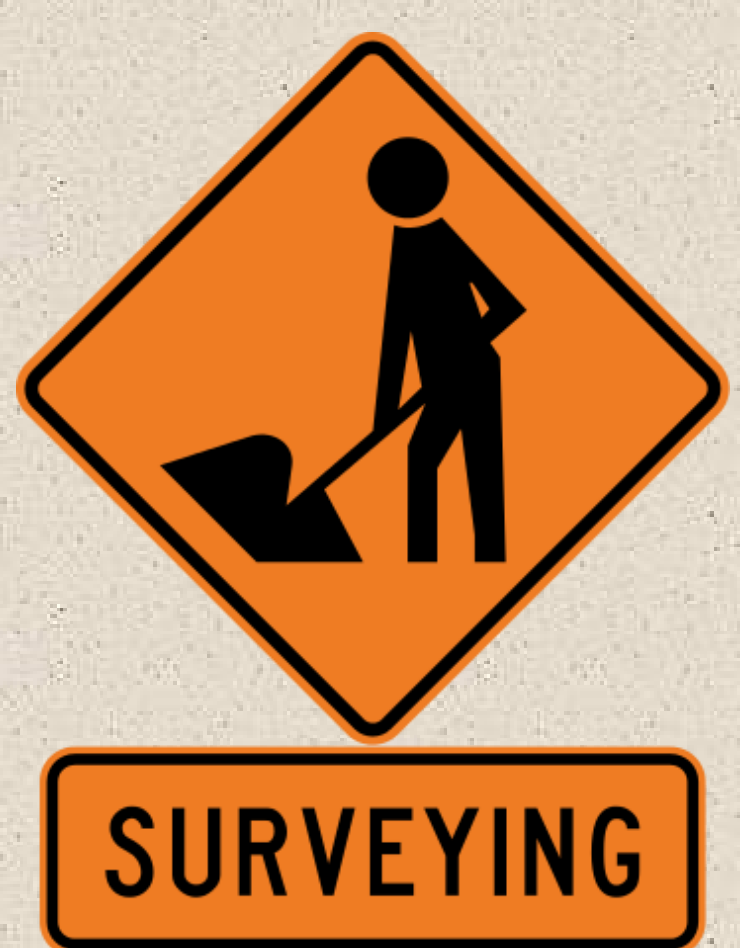

\section{Collection Context}

\section{Excellent}

- Overlap analysis completed

- Fills gap in collection

- Not duplicated

Poor:

- No collection need

- Large amount of duplication 


\section{Content \& Scope}



\section{Curriculum Support}

Excellent:

- Interdisciplinary

- Supports new or developing program/s

Poor:

- Supports one highly specific course...

- ...or none at all 


\section{Library specific concerns}

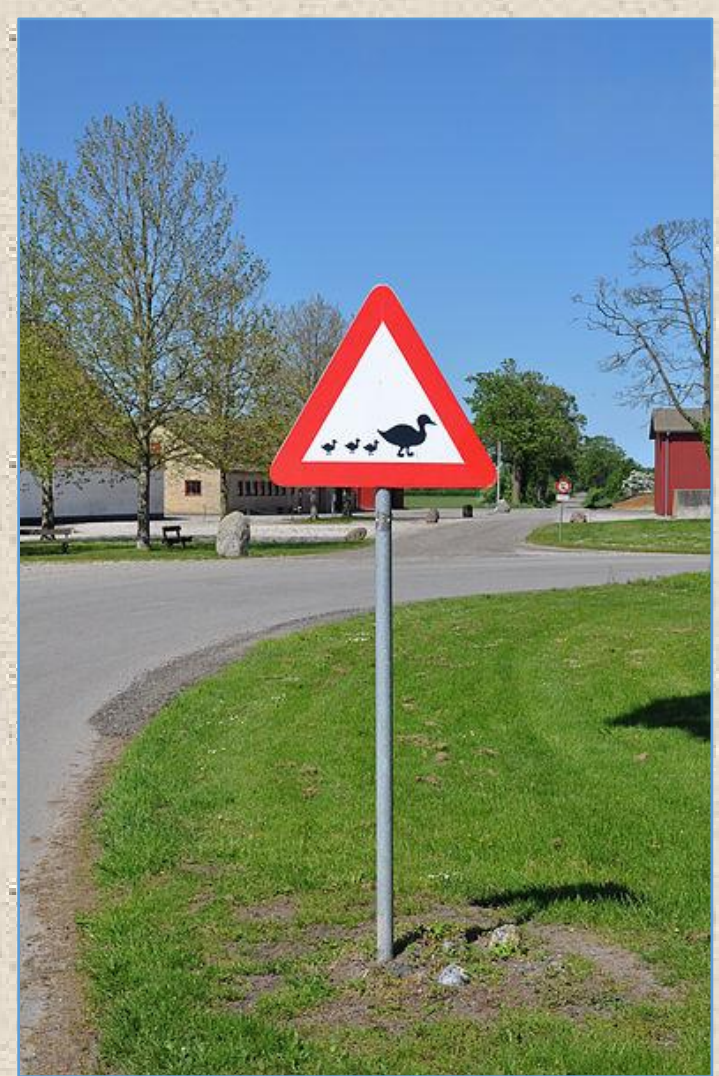

\section{Excellent:}

- EBA available

Access

Based

Models
- Usable

- Affordable

- Manageable

Poor:

No EBA available

Or - available but:

- Unusable

- Unaffordable

- Unmanageable 


\section{Licensing Concerns}

\section{State Requirements}

- Availability of usage statistics

- Indemnification

- Governing law

- Venue

- Term

- Limitation of claims

- Confidentiality

\section{Library Concerns}

- Authorized users

- Interlibrary Loan

- Course-packs/reserves

- Ability/permission to mine data

- Type or quality of perpetual access 


\section{Governing Law}

- Excellent: Listed in license as Texas

- Medium: No mention of governing law

- Poor: Listed in license as a state besides Texas






\section{Term (time limit)}

- Excellent: Exact time period is specified and covers only current fiscal year

- Medium: Exact time period is specified and covers more than current fiscal year-we must add a clause allowing us to break contract in case of budget cuts

- Poor: Exact time period covered is not specified






\section{Confidentiality}

- Excellent: No clause contained in license

- Medium: Clause limited to language of Texas Public Information Act

- Poor: License contains a clause






\section{Library Concerns}

- Authorized users

- Interlibrary Loan

- Course-packs/reserves

- Ability/permission to mine data

- Type or quality of perpetual access

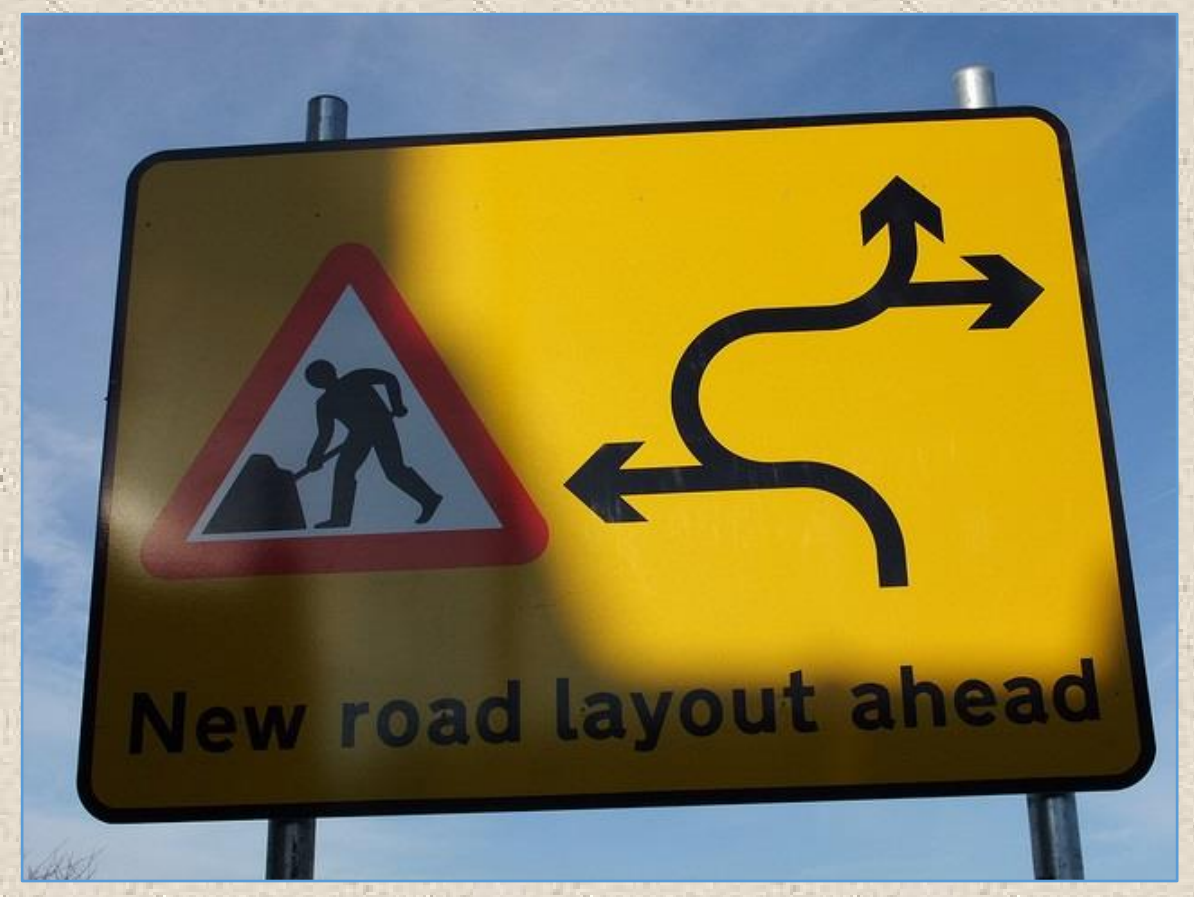




\section{Availability of Usage Statistics}

- Excellent: Usage data available and COUNTER compliant

- Medium: Usage data available but not COUNTER compliant

- Poor: Usage data not made available by vendor

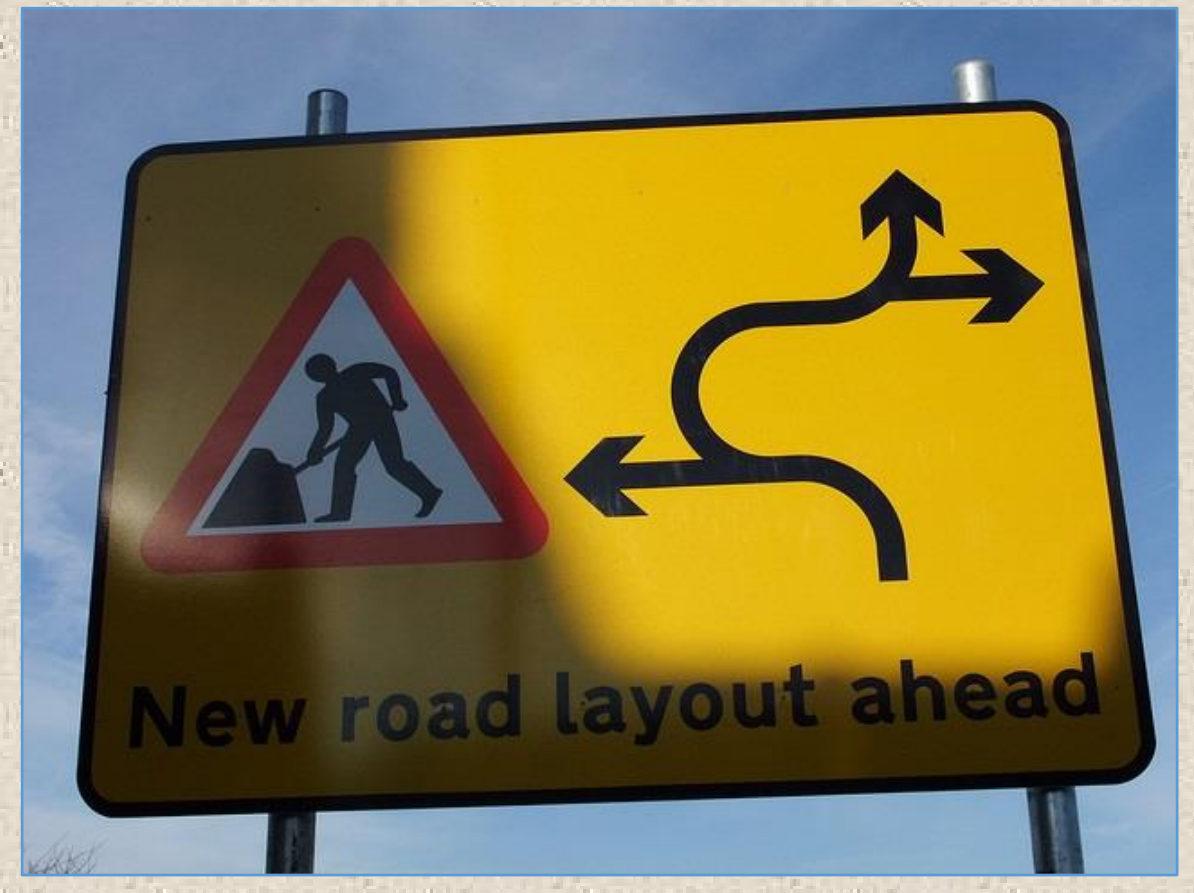




\section{Ability/Permission to Mine Data}

- Excellent: Permitted explicitly

- Medium: Neutral language

- Poor: Prohibited

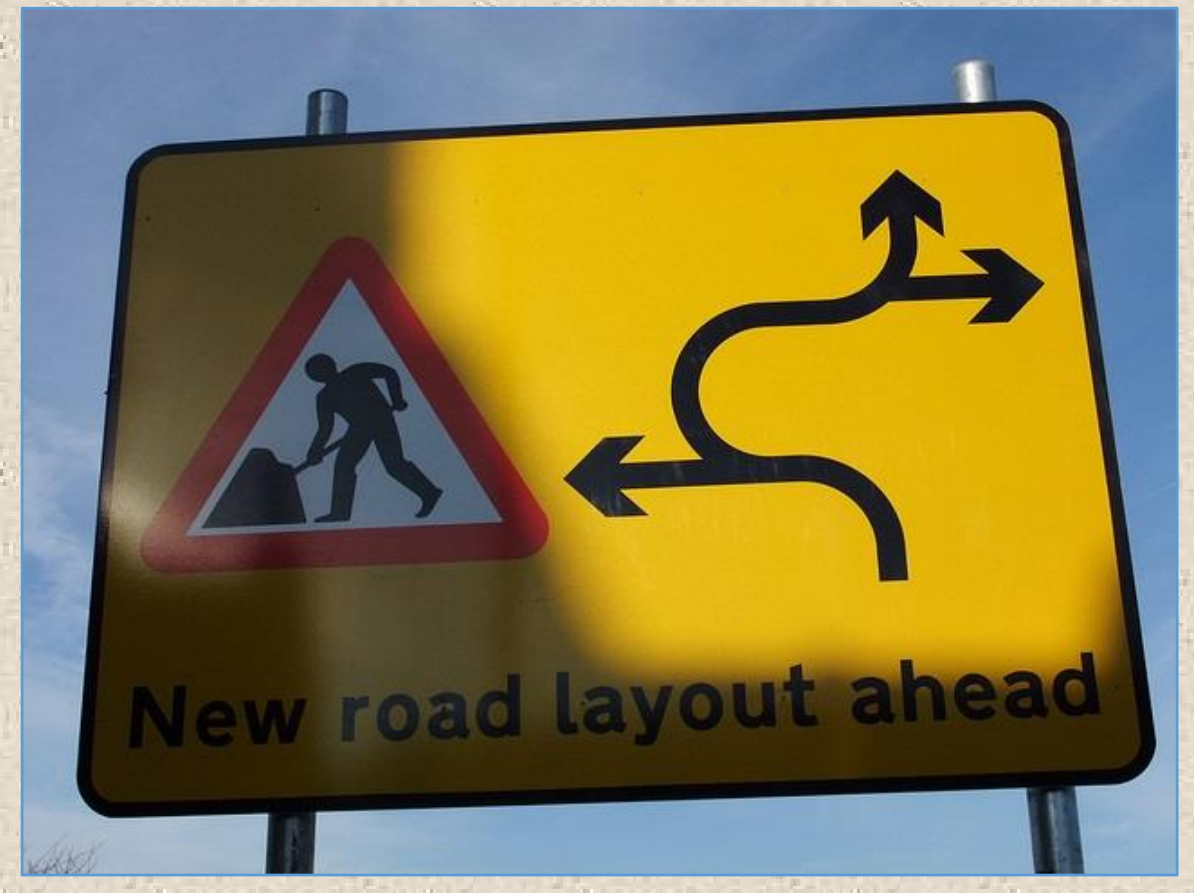




\section{Contracts \& Licensing Checklist}

- Outsources timeconsuming review process

- Allows for two sets of eyes on the process

- Pauses process for negotiation
Interlibrary loan



$\square$ Course packs

Perpetual access, if applicable
Electronic permitted, no record-keeping requirements, and no deletion at end of semester

Electronic not permitted; record keeping requirements; deletion at end of semester (flag)

$\square$ Not permitted (flag)

$\square$ Other:

Contains perpetual rights language and fees are specific

$\square$ Add perpetual rights language and specify fees (flag)

Oother: 
What do we do with the contracts info?

- Evaluate

- Negotiate

- Dictate

- Decide

- Communicate

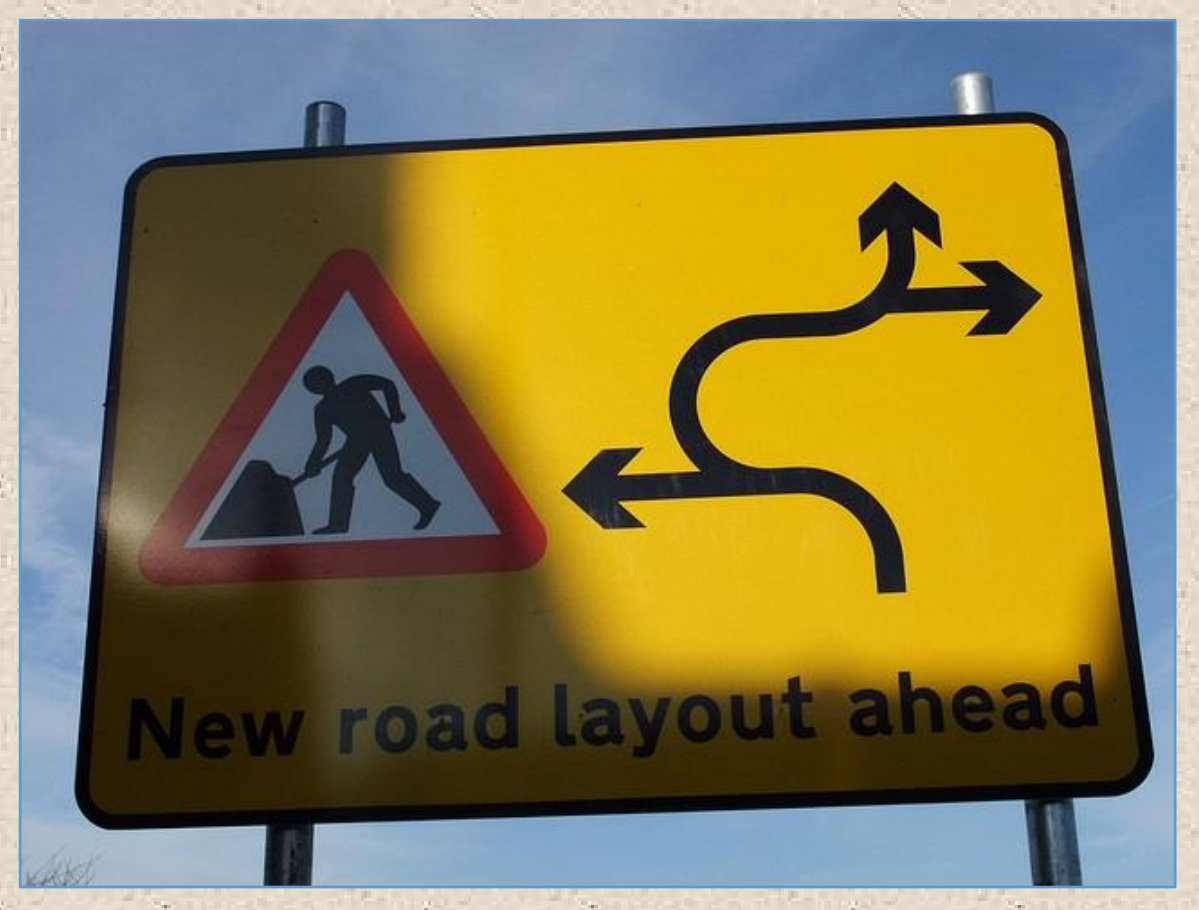




\section{Usability}

\begin{tabular}{|l|l|l|l|}
\hline \multicolumn{1}{|c|}{ A B } & \multicolumn{2}{|c|}{ C } \\
\hline Usability & Excellent & Medium & \\
& & & \\
\hline
\end{tabular}

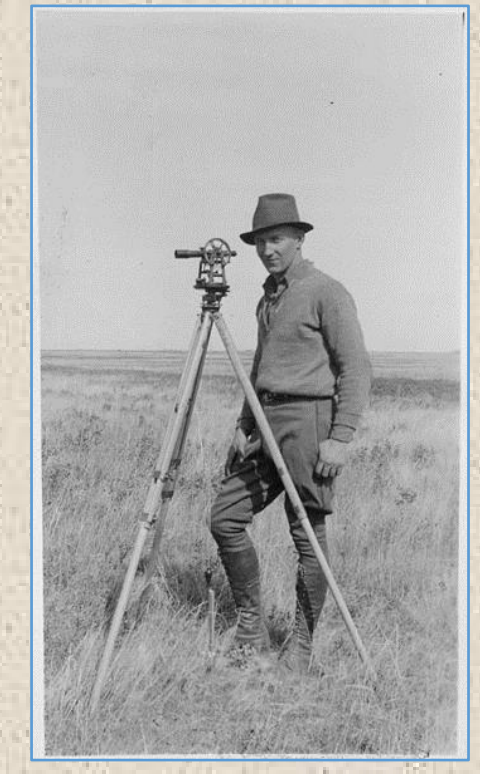

Recommended Usability Metrics:

- Task success measures

- Efficiency

o i.e. task completion time

- Comparing metrics

- Overall usability

- Measure multiple metrics

(Tullis \& Albert, 2013) 


\section{Usability rubric -- content}

\section{Abstracts}

- Available for all content?

Full Text Availability

- Available for all content?

Media

- Multiple media formats included? 


\section{Usability rubric -- content}

\section{References}

\section{Excellent:}

- Displays alongside full-text

- Exports to various citation managers

- RefWorks

- Multiple formats available within the platform

\section{Poor:}

- Not available to format within the platform

- Do not export directly to Refworks 
Usability rubric -- content

Online Help Pages/ Tutorials

\section{Excellent:}

- Available

- Easy to find

- Include both text, video and LibGuides

- Applicable

\section{Poor:}

- Difficult to find or unavailable

- Outdated or irrelevant 


\section{Usability rubric -- functionality}

\section{Discovery}

- Across both index and full-text

\section{Output Options}

- Easy to download, print, email, share via social media, etc.

\section{User Accounts}

- Easy to accomplish

- Not required 


\section{Usability rubric -- functionality}

Search Methods

\section{Excellent:}

- Multiple methods (simple, advanced, browsing, etc.)

- Easy to narrow retrieval within results

- Easy to save search for future replication

\section{Search Techniques}

\section{Excellent:}

- Boolean operators, truncation, proximity searching

- Spellcheck

- Good browsing options 
Usability rubric -- appearance

Search Screens

Excellent:

- Easy to find

- Easy to use

Search Results

Excellent:

- Display limited to a few results or a longer list

- Format of each result is clearly demarcated 


\section{Usability rubric -- appearance}

Mobile Content

\section{Excellent:}

- Renders well on:

- Mobile

o Tablet

\section{Readability}

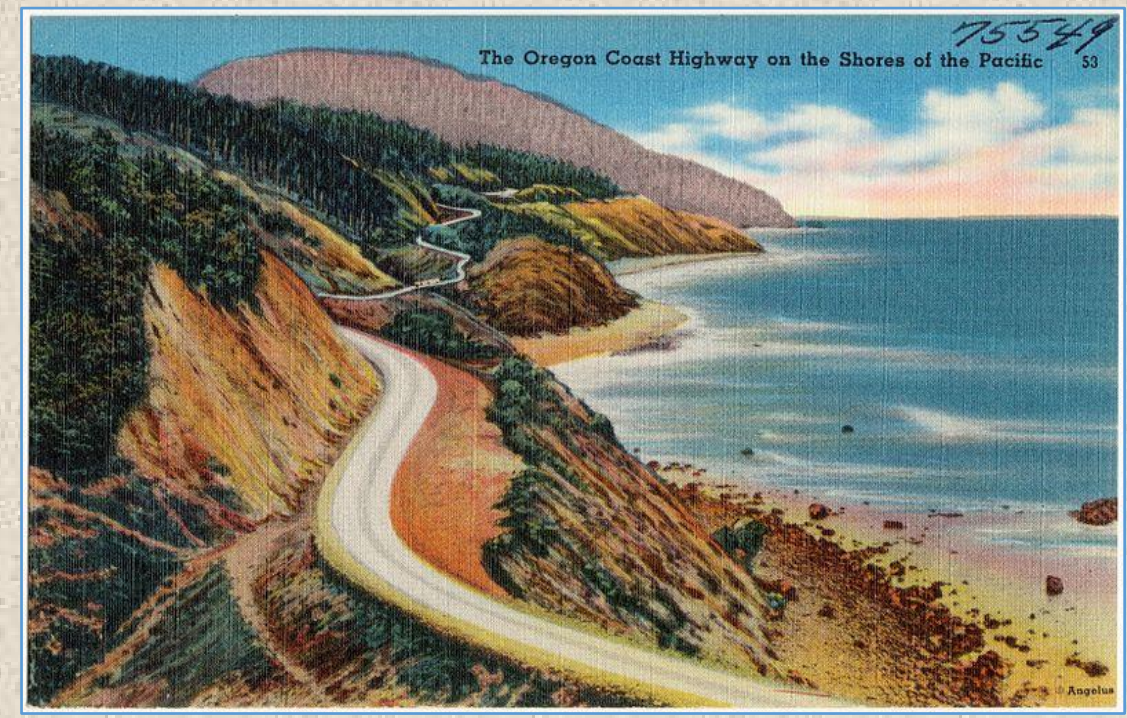

Excellent:

- Text is easy to read and easy to re-size

- Headers and borders are appropriately sized

- Sufficient color contrast on page 


\section{Usability}

\section{Student Evaluations:}

- Define terms in the rubric

- Abstract

- Citation

- Index

- Subject Headings

- Provide Questions or Search Terms

- Specify Advanced Search Use

- Install Chrome Mobile Emulator

o Train on CME

Evaluation Rubrics

There are two ways to do the usability evaluation: use either the online form or the excel spreadsheet. If you

use the spreadsheet you will need to email the results to erin.miller@unt.edu

2 Excellent Usability Eval Online

First fill in the name of the online

Medium resource you are evaluating, your name, Poor your grade level and today's date. Then read through each of the options for each resource characteristic (abstracts, full text availability, etc). Choose the option that best describes the resource you are evaluating. It may take several minutes to look at the resource to find out. You may want to use the help pages in the resource.



Usability Eval Excel File

First type the name of the online

resource you are evaluating at the top of

the spreadsheet. Then highlight the

appropriate choice for each option. At the bottom of each column add up the number of each rating (exellent/medium/poor). 


\section{File Structure}

A folder for everything....and everything in a folder...

- Evolving from a paper-based heritage

- Preparing for the inevitability of turnover

- Creating \& Implementing:

- Shared Folders

- No Duplicates

- Naming conventions 


\section{Workflow}

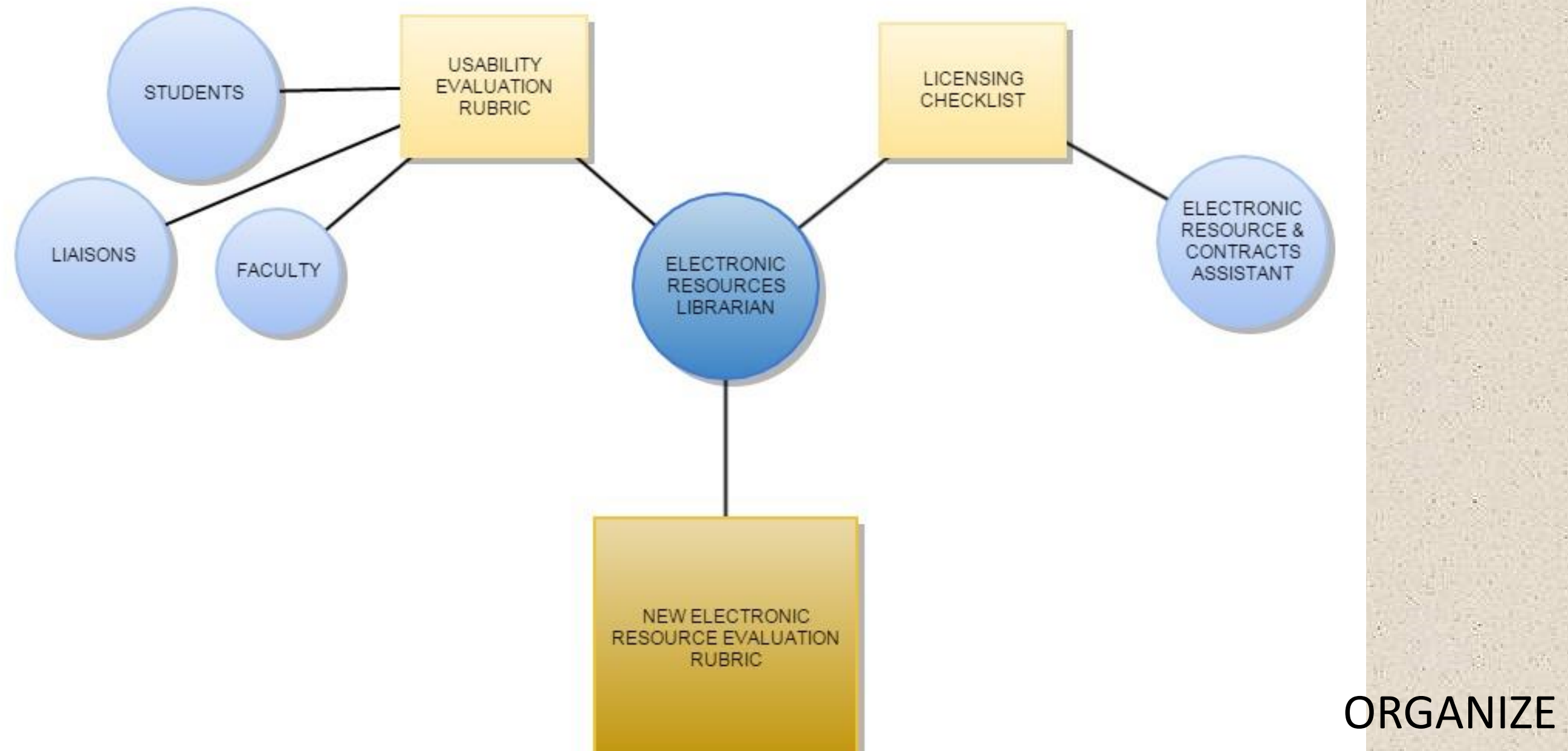


Where do we go from here?

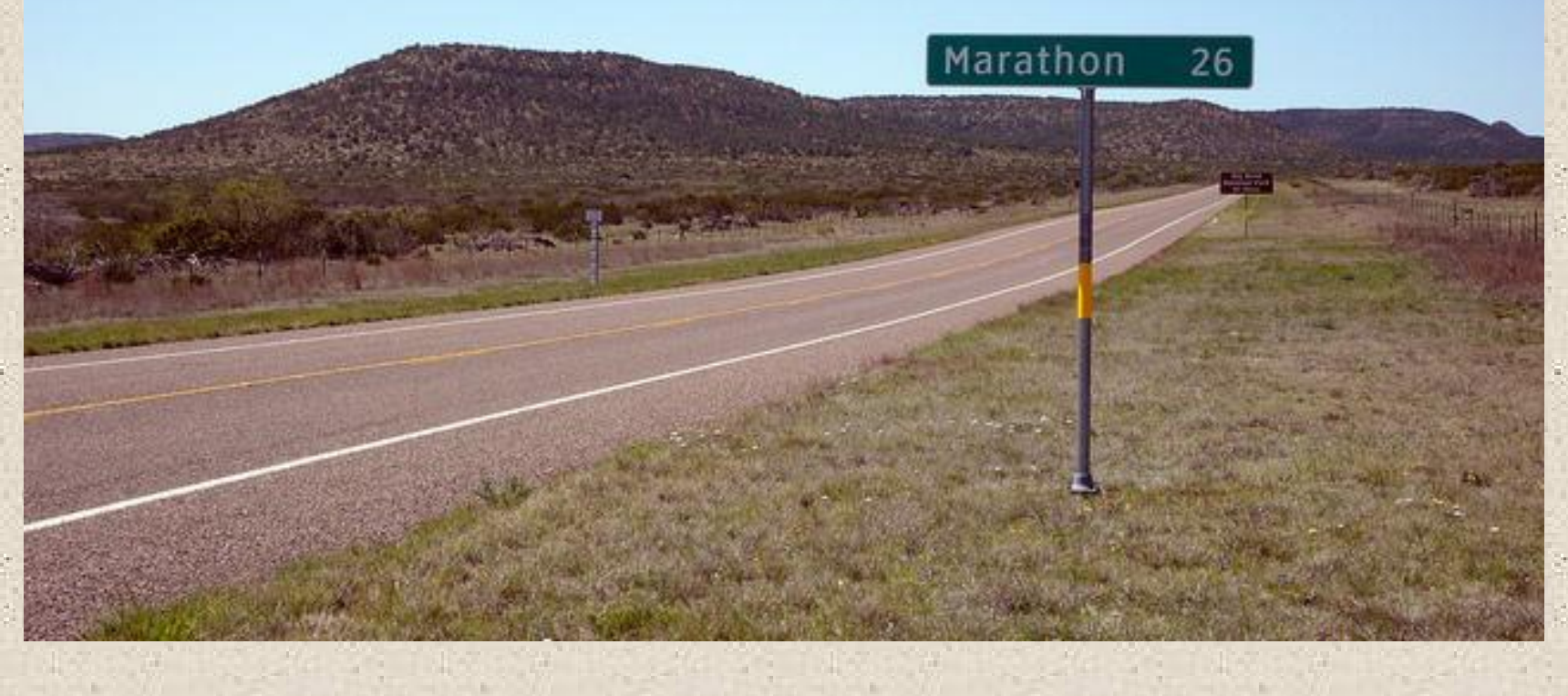

Marathon, 26 miles by Matthew Rutledge, 2010. Available under a Creative Commons 
References:

IRM Program for Accessible Computer/Communication Technology (IMPACT): (2015). Voluntary product accessibility template (VPAT) policy \& information. Retrieved October 13, 2015, from http://www.state.gov/documents/organization/126552.pdf.

Libraries for Universal Accessibility. (2015). VPAT repository. Retrieved Octọber 12, 2015, from http://uniaccessig.org/lua/vpatrepository/

Tullis, T., \& Albert, B. (2013). Measuring the user experience: Collecting, analyzing, and presenting usability metrics (2nd ed.). Waltham, MA: Elsevier, Inc. 